\title{
SEISMIC GROUND RESPONSE ANALYSES AT AN INTERNATIONAL AIRPORT IN NORTHERN ITALY BY USING A STOCHASTIC-BASED APPROACH
}

\author{
Francesca Bozzoni, Ali G. Ozcebe, Andrea Balia, Carlo G. Lai, \\ Barbara Borzi, Roberto Nascimbene, Diana Khairy, Giammaria Gabbianelli \\ European Centre for Training and Research in Earthquake Engineering, Eucentre, Pavia, Italy \\ e-mail: francesca.bozzoni@eucentre.it \\ Lucia Ippoliti, Simona Berardi, Marco Trombetti \\ Italian Civil Aviation Authority, Rome, Italy
}

Claudio Moroni

Italian Department of Civil Protection, Rome, Italy

\begin{abstract}
Airports play a crucial role in mitigation of seismic-induced disasters, being key elements in rescue operations after an earthquake. Under earthquake loading, various airport components can be damaged because of the ground shaking. It is well known that seismic amplification of ground motion at the surface is strongly influenced by geotechnical properties of the soil deposits. In this paper, the spatial variability of ground amplification is assessed with reference to an international airport in Northern Italy. Homogeneous zones from a seismic geotechnical viewpoint were identified at the airport and, for each zone, stochastic ground response analyses carried out.
\end{abstract}

Keywords: airport, ground response, seismic microzonation, stochastic mechanics, GIS (Geographical Information System)

\section{Introduction}

The air transportation network has grown significantly during the past few decades and now represents one of the most critical infrastructures whose disruption would significantly affect the economy, security and overall well-being of a Country.

Experience gained from past and recent earthquakes (e.g. Alaska, 1964; Loma Prieta, California, 1989; Nisqually, Washington, 2001; Port-au-Prince, Haiti, 2010; Puebla, Mexico 2017) has demonstrated seismic vulnerability of airport facilities and damage that can be caused by ground shaking as well as co-seismic effects (e.g. Nisqually Earthquake Clearinghouse Group, 2001). Damage suffered by the airport facilities under seismic loading adversely affects serviceability of airport components with long-term effects due to the time required to restore the operating conditions. Due to the strategic role played by the airports, damage to these infrastructures may also be detrimental during emergency and rescue operations in the immediate aftermath of an earthquake.

Despite the significant role that airports play in the mitigation of seismic-induced disasters, only few studies have addressed the vulnerability of their facilities and the stability of airport subsoil deposits (e.g. Meyer et al., 2001; Wilcoski and Heymsfield, 2002; Vafaei and Alih, 2018; Moravej and Vafaei, 2019).

In Italy, the Department of Civil Protection (DPC) has funded to the European Centre for Training and Research in Earthquake Engineering, Eucentre (Pavia, Italy), a research project on developing tools to assess the seismic vulnerability and risk of the airports nationwide, owning 
support of the Italian Civil Aviation Authority (ENAC). More specifically, an inter-institutional agreement involving these institutions was signed. The main goal of this project is development of a web-based GIS (Geographical Information System) platform which allows users to consider and evaluate jointly different factors that contribute to the seismic risk of airports. The webGIS platform is a robust engine capable of processing basic information and compute newly-generated data such as seismic damage scenarios of airport infrastructures also in the immediate aftermath of an earthquake. In the framework of the mentioned inter-institutional agreement, the webGIS platform developed at Eucentre will become a shared and effective tool for both computation of damage scenarios after an earthquake and assessment of seismic risk of airport infrastructures. Although the project is multi-disciplinary, this paper focuses on activities carried out with reference to an international airport located in Northern Italy, jointly selected as a pilot case study. According to the Italian law (DPR, 2015), in Italy there are 38 airports of national interest, and 3 are intercontinental airports. The airport under investigation features flights to many European metropolitan areas as well as some partly seasonal long-haul routes to the United States, Canada, South Korea and the Middle East, eventually handling more than 11 billion passengers. The seismic geotechnical characterization of the airport area was based on the data from in-situ geotechnical and geophysical investigation campaigns kindly provided by the Airport Authority as well as on the geological information retrieved from the literature. Proper interpretation of the acquired data led to definition of a ground model to be used as a reference for site response analyses. Indeed, within the airport area, different homogeneous zones were identified and then modelled as a series of one-dimensional (1D) soil stratigraphy having parallelly distributed soil layers subjected to vertically propagating plane SH-waves. With reference to each zone of the airport (and hence for each vertical soil column), 1D fully stochastic linear-equivalent ground response analyses have been carried out by using a computer program set-up at Eucentre, named Stoch-Shake. Stoch-Shake has been applied to a significant number of case studies (e.g. Lai et al., 2009; Bozzoni et al., 2011, 2012; Rota et al., 2011; Tarque et al., 2013; Zembaty et al., 2015; Andreotti et al., 2018, etc.). The algorithm is based on adopting the Latin Hypercube sampling technique associated with Monte Carlo simulation. Herein, for the first time, this stochastic-based approach has been applied to assess the seismic ground response of an airport area, taking into account uncertainty of each soil model parameter as well as variability of the seismic input.

In summary, a special attention was paid to quantifying spatial variability of possible effects of ground amplification on the soil surface of the airport area due to local site conditions. It is worth noting that any kind of soil-structure interaction has been disregarded, the results are shown for free-field conditions with the absence of structural components.

\section{Methodology to assess effects of ground amplification}

This Section includes two parts, i.e. the first in which general concepts on ground amplification effects are illustrated and the second focusing on the approach to carry out the ground response analysis adopted in this study.

\subsection{General concepts}

Local amplification effects refer to those phenomena that modify the expected ground motion on rock outcropping predicted by a macrozonation map derived from a regional scale seismic hazard assessment. This happens because geological and geotechnical characteristics at a site can exert a strong influence on the nature of seismic ground shaking experienced by structures, and it has been recognized that earthquake damage is generally larger over soft sediments than on firm bedrock outcrops. Several are examples worldwide where urban aggregates located at 
large distances from the epicenter of an earthquake have suffered severe damage and destruction (e.g. Faccioli, 1991).

The case of the Michoacán earthquake of 19 September 1985 on the coast of Mexico demonstrated that site effects can completely dominate the seismic hazard at a site. The nature of ground motion was so diverse within Mexico City, about $400 \mathrm{~km}$ from the earthquake source, that some parts of the city experienced very strong shaking causing great destruction, whereas in some others people did not even realize that there was an earthquake. The 1963 Skopje earthquake in Macedonia represents a good example in Europe of the role that the ground response may play in determining the damage pattern caused by a seismic event. Localized amplification of strong ground motion may be due to either peculiar geological, geomorphological features of soil deposits or due to the presence of lithostratigraphic and/or topographic irregularities within the site.

The estimate of modification of ground motion due to the aforementioned local characteristics at an urban scale is known as seismic microzonation. Following the guidelines set by the Technical Committee 4 (TC4) of the International Society of Soil Mechanics and Foundation Engineering (ISSMGE, 1999), microzonation for a local ground response of a territory may be conducted according to three possible levels of refinement and spatial resolution. This depends on the degree of knowledge and available information and also whether the zonation is achieved through compilation and interpretation of existing geological and geomorphological data or on the basis of detailed and purposely-planned geotechnical and geophysical investigation campaigns possibly followed by ground response analyses. The most refined level is constructed based on detailed site investigations of the territory under study coupled with a full set of $1 \mathrm{D}$ and, if required, 2D and possibly 3D numerical ground response analyses.

Characteristics of earthquake ground motions describing the input motions for structures standing on ground deposits are affected by three factors:

(i) source characteristics (such as geometry and kinematics of the rupture),

(ii) propagation path (i.e. crustal layers that seismic waves go through),

(iii) local site conditions (i.e. presence of superficial soil layers, basin structures, surface topography).

Although it is possible to cover the whole passage from (i) to (iii), it still requires significant knowledge and associated uncertainty in the estimation of future scenarios. Hence, in current days, often the first two steps are by-passed by selecting a proper set of ground motion that somehow represents their inherent variability, and the focus is given to (iii). Such an approach is also called the site (or ground) response (Kramer, 1996) study, which aims at quantifying amplification characteristics of a site that is well-defined in terms of its geotechnical and geophysical properties. Depending on the level of knowledge and necessity, the site response analyses may be done by considering $1 \mathrm{D}$ propagation of plane waves and 2D propagation of incident vertically propagating plane waves. 3D analyses could be also made, however given their complexity, they are preferred usually when source-to-site propagation is investigated (e.g. Paolucci et al., 2014).

\subsection{Stochastic-based approach adopted to carry out ground response analysis}

The site response analysis is strongly influenced by the uncertainty associated to the definition of soil properties and model parameters (Assimaki et al., 2003). Moreover, a given site may be affected by a variety of earthquakes each with different characteristics in terms of the frequency content, duration, correlation between phases and components (Boore, 2004). As raised by Rota et al. (2011), quantifying the uncertainty associated to the model is not trivial, since this is affected by a combination of epistemic (lack of knowledge) and aleatory (related to the intrinsically stochastic nature of model parameters) uncertainty. Since a deterministic or even 
a parametric analysis cannot capture the uncertainty in the dynamic soil properties and in the definition of the soil model parameters, stochastic analysis should be performed.

A fully stochastic-based approach has been adopted in this study to carry out ground response analysis evaluating systematically the sensitivity of motion computed at the free surface to the aleatory uncertainty associated to geotechnical parameters as well as to the reference object motion.

A computer program for performing 1D fully stochastic linear-equivalent ground response analyses of soil deposits, named Stoch-Shake, has been set-up at Eucentre and applied to a significant number of case studies (mentioned in Section 1). Through a large number of numerical simulations, the influence of the variability of single parameters and of their combination on the surface ground motion can be assessed. The algorithm is based on adopting the Latin Hypercube sampling technique associated with Monte Carlo simulation. It consists in iterative runs of a deterministic model, whose input parameters are defined, at each iteration, by a set of random realisations of previously defined probabilistic distributions.

Concerning the reference seismic input, a computer program, named ASCONA (Corigliano et al., 2012), set-up at Eucentre, has been adopted for selecting real, spectrum-compatible records. This code was also used to build Seism-Home portal (Rota et al., 2012) linked to the Eucentre website: http://www.eucentre.it/seismhome.html. Seism-Home allows downloading suites of 7 real spectrum- and seismo-compatible accelerograms for any location of the Italian territory for outcropping rock conditions for the standard return period of 475 years.

For each analysis and a specific return period, one out of the 7 real accelerograms, is randomly selected and applied as the object motion. Shake91 (Schnabel et al., 1972; Idriss et al., 1990) performs automatically deconvolution of the signal and performs the analysis in terms of total stresses. Strains and stresses are computed at various depths together with time histories of acceleration, velocity and displacement. To sum up, the overall procedure that Stoch-Shake follows could be explained in a nutshell, as below:

- Definition of probabilistic distributions of all input parameters;

- Generation through the Monte Carlo algorithm coupled with the Latin Hypercube sampling technique of a large number $(>1000)$ of random realizations of geotechnical parameters and object motions through the purposely developed computer code;

- For each random realization of input parameters, the code: i) creates an input file for Shake91, ii) runs Shake91, iii) reads the output file and saves results;

- The results of all runs and output data are statistically processed and analysed.

\section{Expected ground motion at the airport case study}

In the framework of the project commissioned by DPC to Eucentre on assessing the seismic vulnerability and risk of the most relevant Italian airports, an international airport was jointly selected with ENAC as the pilot case study. The first step in the seismic risk assessment is herein represented by computation of ground amplification effects in the airport area.

The seismic geotechnical characterization of the airport area was defined based on the data from in-situ geotechnical and geophysical investigation campaigns provided by the Airport Authority. The geological setting was defined based on the data retrieved from previous studies. A GIS database was constructed to visualize and process the acquired data which led to definition of a seismic microzonation map of the airport area. Different homogeneous zones were identified, and for each one of them a site-specific geotechnical model was defined. This was later used for ground response analyses by adopting the stochastic-based procedure (i.e. the Stoch-Shake code) briefly illustrated in Section 2. 


\subsection{Definition of the reference seismic hazard}

The reference seismic hazard (referred to outcropping rock and ground-leveled topographic conditions) at the airport site was defined within a probabilistic framework according to the prescriptions of the current Italian building code (NTC, 2018; Circ. NTC, 2019).

The Italian building code defines the design spectrum at each site of a grid covering the whole territory, starting from the results of probabilistic seismic hazard assessment (PSHA) of Italy carried out from 2003 to 2009 by a working group established by the Italian Institute of Geophysics and Volcanology (Istituto Nazionale di Geofisica e Vulcanologia, INGV). In this PSHA study, the reference seismic hazard was computed for more than 16000 points of a regular grid of $5 \mathrm{~km}$ in terms of peak ground acceleration (PGA) on rock for nine probabilities of exceedance in 50 years (i.e. $2 \%, 5 \%, 10 \%, 22 \%, 30 \%, 39 \%, 50 \%, 63 \%$, and $81 \%$ ) and spectral accelerations for 10 periods (to define the uniform hazard spectrum) for all nine probabilities of exceedance. It is worth mentioning that a $10 \%$ probability of exceedance in 50 years corresponds to a return period of 475 years. The spectral shape of NTC (2018) is based on the definition of three parameters for each return period: the peak ground acceleration - in the Italian building code, the ag symbol stands for PGA on rock - and two additional parameters that allow the spectral shape to more closely fit the uniform hazard spectrum; these two parameters are the corner period $\left(T_{C}^{*}\right)$ and the spectral amplification factor $\left(F_{0}\right)$. The interested reader may refer to, among others, Stucchi et al. (2011) for furthers details.

Table 1 contains, for each of the two return periods considered in this study (i.e. 475 and 2475 years), the seismic coefficients provided by the Italian building code to define the code-based response spectra for ground category A at the site of the airport. Table 1 also shows results from deaggregation of the probabilistic seismic hazard study (Spallarossa and Barani, 2007) for the site under investigation.

Table 1. Seismic coefficients to define code-based response spectra, provided by the Italian building code (NTC, 2018) for ground category A (rocky site) and results from deaggregation of the probabilistic seismic hazard study (Spallarossa and Barani, 2007) for the site of the airport

\begin{tabular}{|c|c|c|c|c|c|c|}
\hline $\begin{array}{c}\text { Return period } \\
\text { (years) }\end{array}$ & \multicolumn{2}{|c|}{ Seismic coefficients (NTC, 2018) } & \multicolumn{3}{c|}{ Deaggregation parameters (for $a_{g}$ ) } \\
\cline { 2 - 7 } & $a_{g}[\mathrm{~g}]$ & $F_{0}[-]$ & $T_{C}^{*}[\mathrm{~s}]$ & $M_{W}[-]$ & Dist. $[\mathrm{km}]$ & $\varepsilon[-]$ \\
\hline \hline 475 & 0.086 & 2.597 & 0.357 & 5.65 & 48.30 & 1.56 \\
\hline 2475 & 0.142 & 2.627 & 0.424 & 6.03 & 42.00 & 1.97 \\
\hline
\end{tabular}

The seismic action for each return period is represented in terms of uniform hazard acceleration response spectra and real spectrum-compatible accelerograms on rocky sites. Specifically, for each return period, a set of 7 real, spectrum- and seismo-compatible accelerograms have been selected from accredited strong motion databases. These accelerograms, recorded at outcropping rock sites with a flat topographic surface, are spectrum-compatible with the acceleration response spectrum prescribed by the Italian building code at the site under investigation and also satisfy the requirement of seismic-compatibility, which means that they are consistent with the regional seismotectonic and seismogenic setting. It has been a priori decided to use recorded accelerograms since, according to the current literature and Eurocode (EC8, 2005) recommendations, they are preferred with respect to artificial records, especially for applications in geotechnical earthquake engineering and, in particular, for seismic site response analyses. Furthermore, the use of real time-series as the input to dynamic analyses should be preferred, as they are realistic in terms of the frequency content, duration, number of cycles, correlation among vertical and horizontal components and energy content in relation to seismogenic parameters. The size of the suite of accelerograms has been established equal to 7 , in agreement with the Italian building code (NTC, 2018), which specify that the number of records in the set should be equal or 
larger than 7, if the user wishes to use the average results of the analyses instead of the most unfavorable ones. As previously illustrated, the set of natural accelerograms were obtained from SEISM-HOME for a 475-years return period and by using ASCONA for the set referred to a 2475-years return period.

\subsection{Geological framework and data from geophysical and geotechnical tests}

Seismic geotechnical characterization of the airport area was based on the data from in-situ geotechnical and geophysical investigation campaigns provided by the port authority and also on the geological information retrieved from the literature. Geological information has been obtained from different sources, such as technical reports provided by the Airport Authority and scientific publications.

The area under investigation is located on an alluvial system, i.e. layers of silts, sands and clays typical of the lagoon area where the airport lies. According to gathered information, the layer assumed as seismic bedrock in performing ground response analysis is located at the mean depth of $200 \mathrm{~m}$.

The seismic geotechnical characterization of soil deposits within the airport area was based on the findings of various investigation campaigns performed from 2009 to 2017. 68 boreholes $(\mathrm{BH})$ were drilled and various kinds of in situ tests were executed: 63 Cone Penetration Tests with measurement of the pore water pressure (CPTu), 3 Seismic Cone Penetration Tests (SCPTu), 14 Seismic Dilatometer Marchetti Tests (SDMT), 4 Multi-Channel Analysis of Surface Waves (MASW) and 2 Refraction Microtremor (ReMi) measurements. Data on the grain size distribution of a few samples, taken from soil deposits within the airport area, and their main physical properties were obtained from laboratory tests performed during some investigation campaigns. To manage all the collected data, in particular geotechnical and geophysical data from overall 154 in-situ tests (Fig. 1), a GIS database was purposely built.

\subsection{Subsoil modelling and seismic microzoning of the airport area}

Geological information was analysed in conjunction to geotechnical and geophysical data, provided by the Airport Authority, in order to come up with a detailed and complete description of subsoil conditions at the airport.

The main litho-stratigraphic units of the airport subsoil were identified in this study by using both logs from boreholes drilled at the airport area and soil stratigraphy obtained by applying charts, available in the literature, that link CPTu and DMT measurements to the soil type. Data from $68 \mathrm{BH}, 66 \mathrm{CPTu}$ and 14 DMT were used.

One of the major applications of the cone penetration tests has been the determination of soil stratigraphy and the identification of the soil type. The early charts developed in the Netherlands were based on the measured cone resistance $q_{c}$ and sleeve resistance $f_{s}$ using a mechanical cone, and showed that there was an approximate linear link between $q_{c}$ and $f_{s}$ for a given soil type. Early charts $q_{c}$ and friction ratio $\left(R_{f}=f_{s} / q_{c}\right.$ in percent) were also proposed, but the charts proposed by prof. P.K. Robertson have become very popular. In this study, the most updated version of the method proposed for CPTu by Robertson (2016) has been adopted. Since empirical correlations between the soil type and in situ measurements have significant uncertainty, preliminary validation of this indirect approach has been carried out through comparison of soil types from nearby CPTs and boreholes at the airport.

A similar procedure was adopted with reference to penetration measurements from DMT executed in the area under investigation. More specifically, main litho-stratigraphic units were identified using the indirect method proposed for DMT tests by Marchetti (1980) after validating it through comparison of soil stratigraphy from nearby DMT and boreholes in the airport area. It 


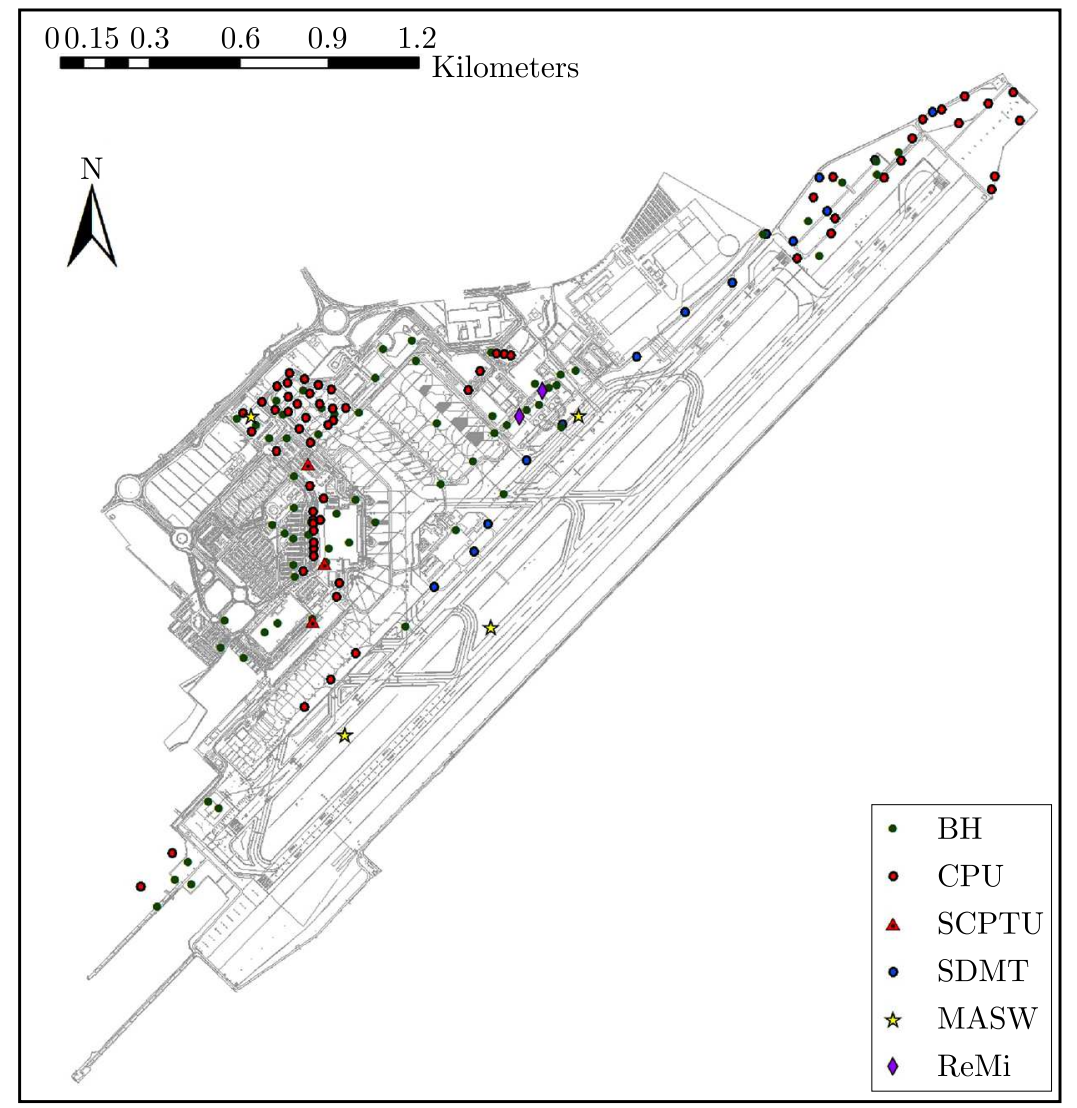

Fig. 1. Map showing location of geotechnical and geophysical in situ tests (overall 154) adopted in this study for ground characterization of the area of the airport

is worth noting that the accuracy of applications of DMT data for identifying litho-stratigraphic units are significantly lower with respect to the applications related to CPTu measurements.

Shear wave velocity $V_{s}$ profiles were obtained starting from direct measurements of $V_{s}$ from SCPTu, SDMT, MASW, and ReMi, performed in the airport area, and $V_{s}$ values computed from $\mathrm{CPTu}$ penetration resistances by using empirical correlation available in the literature (i.e. Mayne, 2007). The preliminary validation of the adopted empirical method has been carried out with reference to a few nearby CPTu and direct measurements of $V_{s}$ (from SDMT) in the airport area.

Proper interpretation of acquired and obtained data led to definition of the ground model to be used as the reference for site response analyses. Figure 2 shows the 3D subsoil model that has been constructed down to about $35 \mathrm{~m}$ depth (from the ground level) with reference to the specific zone within the central part of the airport area where strategic structures such as traffic control tower, fire-fighting, etc. are located.

Different homogeneous zones were identified and then modelled as a sequence of constant thickness, plane and parallel layers corresponding to 1D soil stratigraphy. Having carried out this step, a seismic microzonation map of the airport area (Fig. 3) has been defined in this study. The homogeneous zones are listed in Table 2. Data from geotechnical and geophysical tests performed on the south-eastern part of the airport need to be collected from the Airport Authority.

For zones from Z.1 to Z.8 (except for Z.7 for which $V_{s}$ data are not currently available), a site-specific geotechnical model was defined to be used for ground response analyses. To define such a geotechnical model for a ground response analysis, it is necessary to define the number of layers and then, for each layer, the following parameters: thickness, shear wave velocity, total 


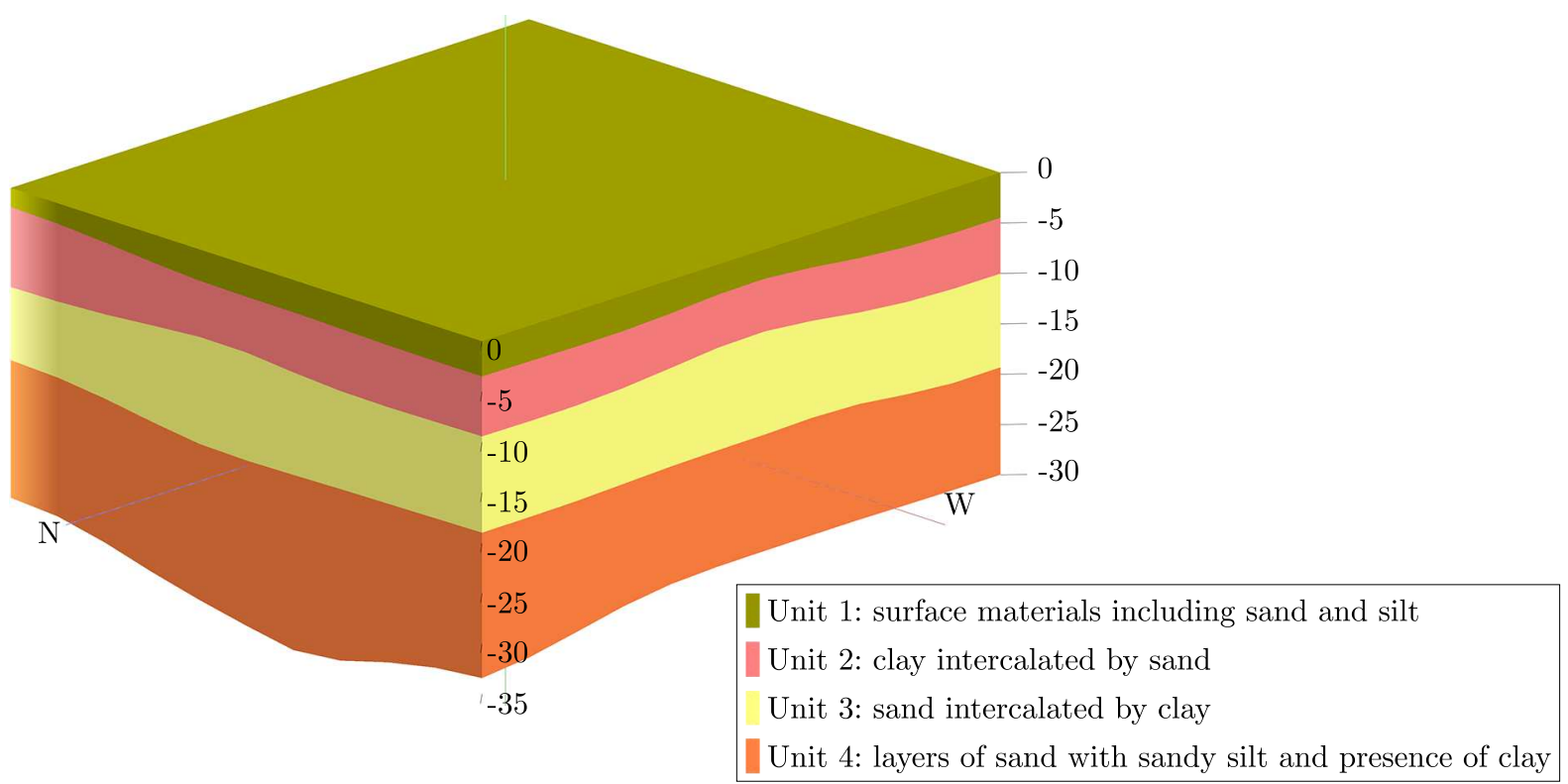

Fig. 2. 3D subsoil model down to about $35 \mathrm{~m}$ depth (from the ground level) built with reference to the central part of the airport area where strategic structures are located

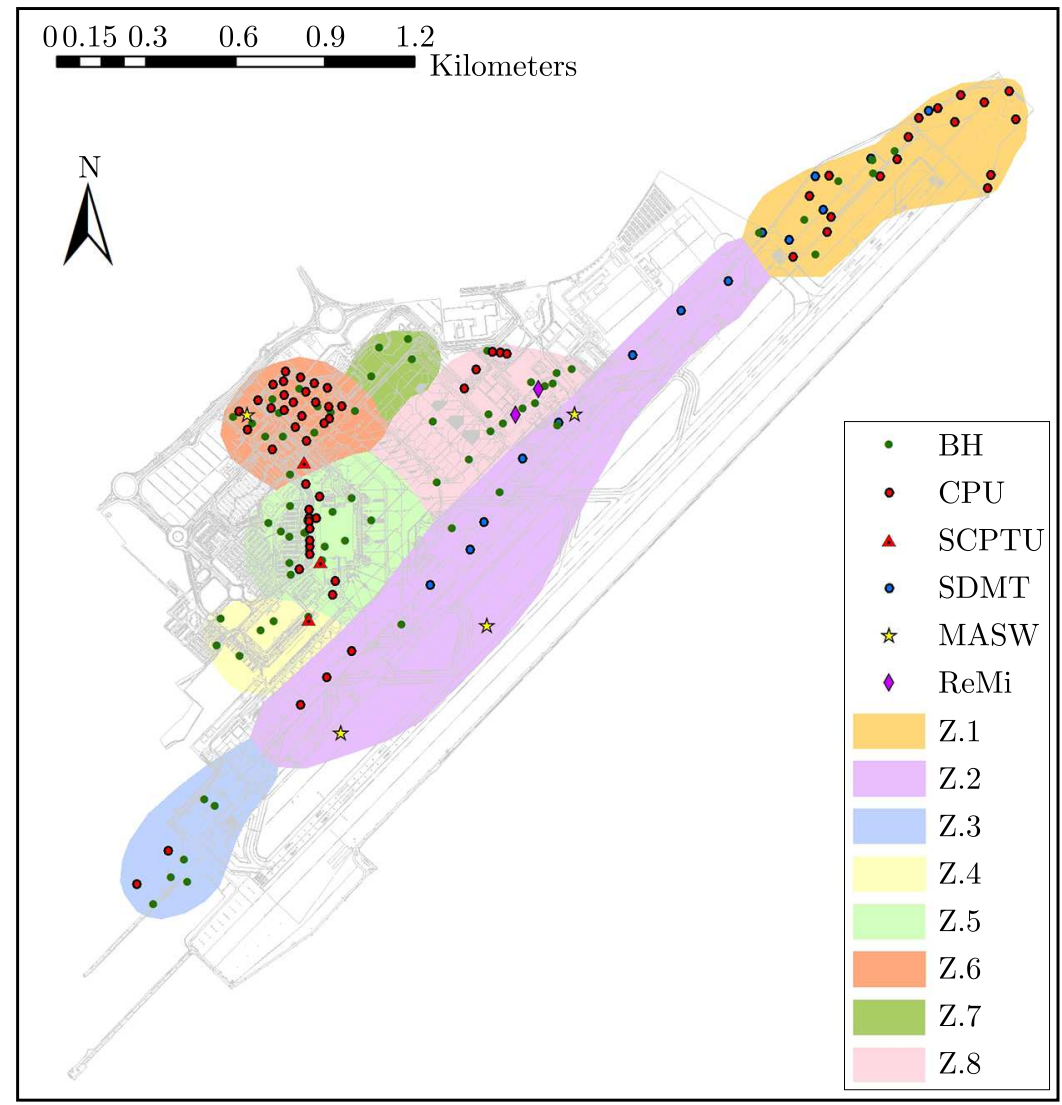

Fig. 3. Seismic microzonation map of the airport area: identification of homogeneous zones from a seismic geotechnical viewpoint 
Table 2. Types and number of geotechnical and geophysical tests for each zone identified in the airport area seismic zonation map shown in Fig. 3

\begin{tabular}{|l|c|c|c|c|c|c|c|}
\hline \multicolumn{1}{|c|}{ Airport zones } & Zone & BH & CPT & SCPT & SDMT & MASW & ReMi \\
\hline \hline Extension of secondary runway & Z.1 & 7 & 17 & - & 6 & - & - \\
\hline Secondary runway & Z.2 & 4 & 3 & - & 8 & 3 & - \\
\hline South-West area & Z.3 & 6 & 2 & - & - & - & - \\
\hline Airport facilities (e.g. parking) & Z.4 & 6 & - & 1 & - & - & - \\
\hline Terminal & Z.5 & 16 & 13 & 1 & - & - & - \\
\hline Airport apron & Z.6 & 11 & 23 & 1 & - & 1 & - \\
\hline Hangar & Z.7 & 4 & - & - & - & - & - \\
\hline $\begin{array}{l}\text { Area of strategic structures (e.g. traffic } \\
\text { control tower, fire-fighting, etc.) }\end{array}$ & Z.8 & 14 & 5 & - & - & - & 2 \\
\hline
\end{tabular}

unit weight of soil and shear modulus and damping degradation curves. At last the values of shear wave velocity and of total unit weight for the half-space are required. Available data do not allow definition of the $V_{s}$ profile for soil deposits deeper than $40 \mathrm{~m}$, thus a hyperbolic law according to Gibson's model (Gibson, 1967; Awojobi, 1975) was adopted.

As the evaluation of the above parameters involves some level of uncertainty, an interval of variation has been associated to each input parameter in the ground model used to perform ground response analyses at the site. The uncertainty has been quantified by identifying intervals of variation of the geotechnical parameters using lower and upper bounds. The assumption used in this work, in light of the available data, is that the experimental interval corresponds to the mean plus or minus 2 standard deviations which for each parameter amounts in assuming that $95 \%$ of the values fall within the experimentally observed interval. A normal probability distribution has then been assumed for thickness, shear wave velocity, total unit weight and parameters to define the shear modulus and damping degradation curves defined according to Darendeli (2001), while the record to be analysed is randomly chosen out of the 7 real accelerograms adopted for each return period by making use of a uniform probability density function.

\subsection{Results from stochastic ground response analyses}

Following statistical characterization of the subsoil models, ground response analyses have been carried out with the procedure, described in Section 2, allowing one to take into account the uncertainties associated to different geotechnical parameters. Through a large number of numerical simulations, the influence of variability of single parameters and of their combination on surface ground motion was assessed. The algorithm is based on adopting the Latin Hypercube sampling technique associated with Monte Carlo simulation. It consists in iterative runs of a deterministic model whose input parameters are defined at each iteration by a set of random realisations of previously defined probabilistic distributions. For each analysis and a specific return period, one out of the 7 real accelerograms is randomly selected and applied as object motion. Shake91 performs automatically deconvolution of the signal and performs analysis in terms of total stresses. Strains and stresses are computed at various depths together with time histories of acceleration, velocity and displacement. The dynamic response of soils is nonlinear even at low to moderate deformation levels. Shake91 take these manifestations of soil behaviour into account using a linear-equivalent, viscoelastic constitutive model.

The variability of the soil model used in stochastic analyses with reference to the zone named Z.1 (extension of the secondary runway) in the airport area is shown in Fig. 4a, which illustrates 1000 shear wave velocity profiles corresponding to random realizations of $V_{s}$ extracted 
from statistical distributions of $V_{s}$ and thicknesses of different layers. The variability of model parameters obviously determines variability in the results obtained from the analyses. Figure $4 \mathrm{~b}$ shows the elastic acceleration response spectra computed for each of the 1000 simulations of input parameters overlapped to the mean and median spectra for the 475-year return period. The observed dispersion is strongly controlled by the variability of shear wave velocity profiles and by the frequency content and intensity characteristics of the input motion.

(a)

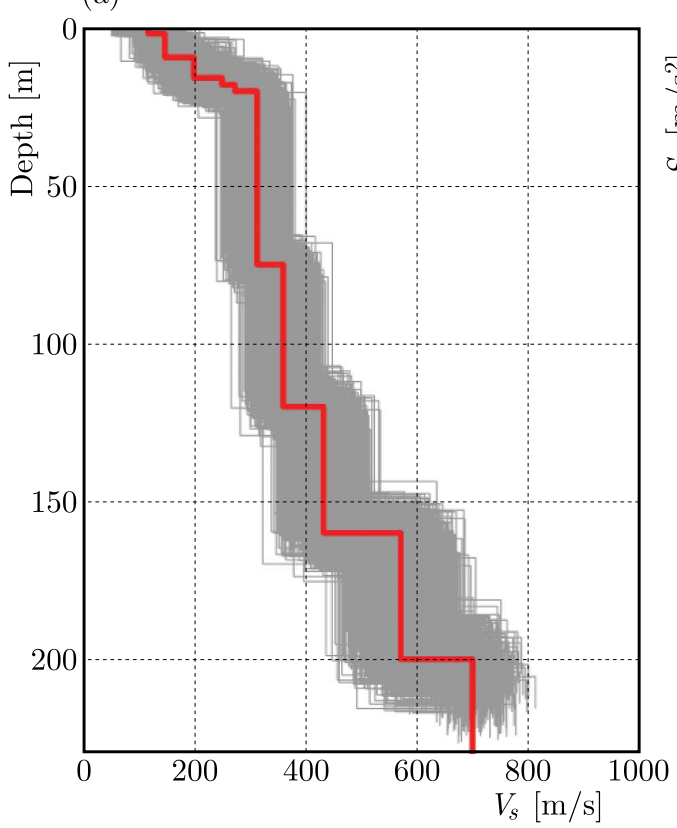

(b)

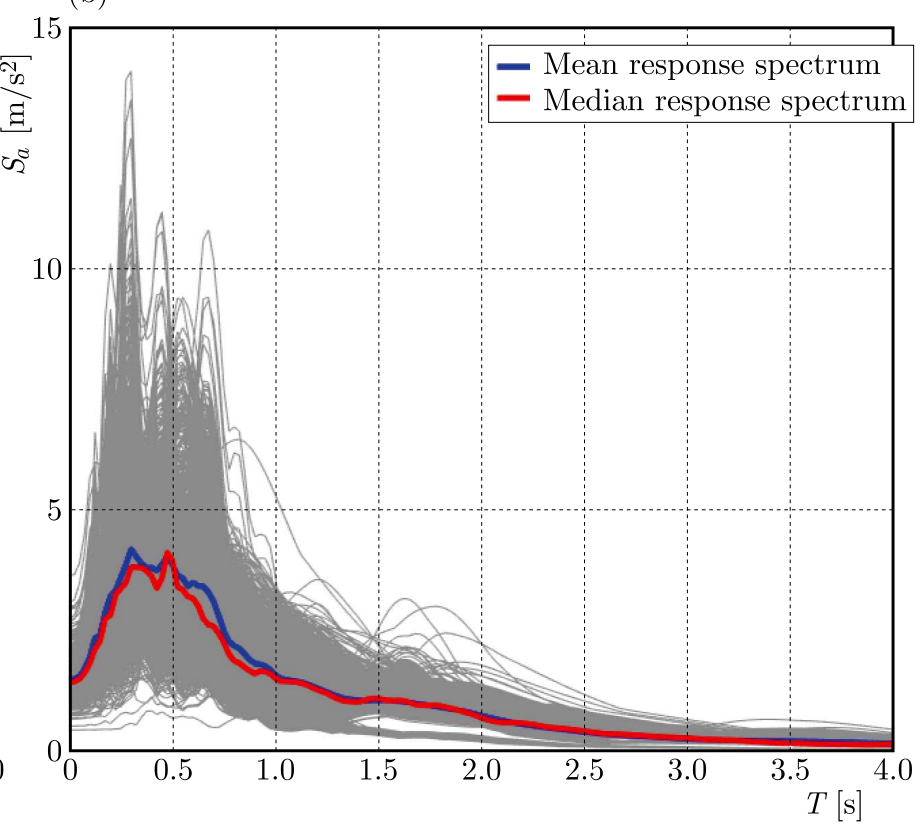

Fig. 4. Stochastic ground response analysis for zone Z.1 (extension of the secondary runway) in the airport area referred to 475-years return period: (a) 1000 random $V_{s}$ profiles (grey lines) generated adopting the Latin Hypercube sampling technique associated with Monte Carlo simulation; the red line represents the mean profile, (b) acceleration response spectra computed out of 1000 numerical simulations (grey lines) and also mean (blue line) and median spectra (red line)

(a)

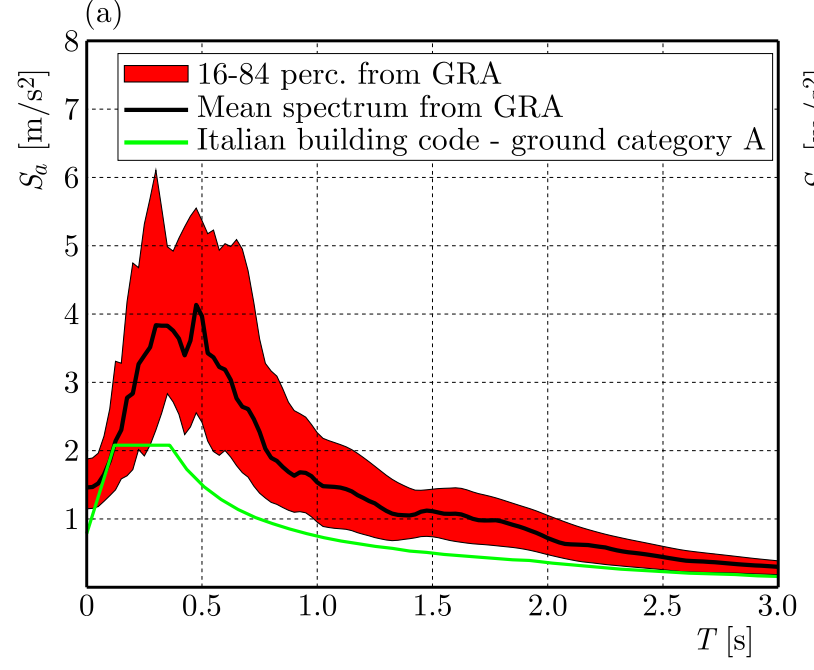

(b)

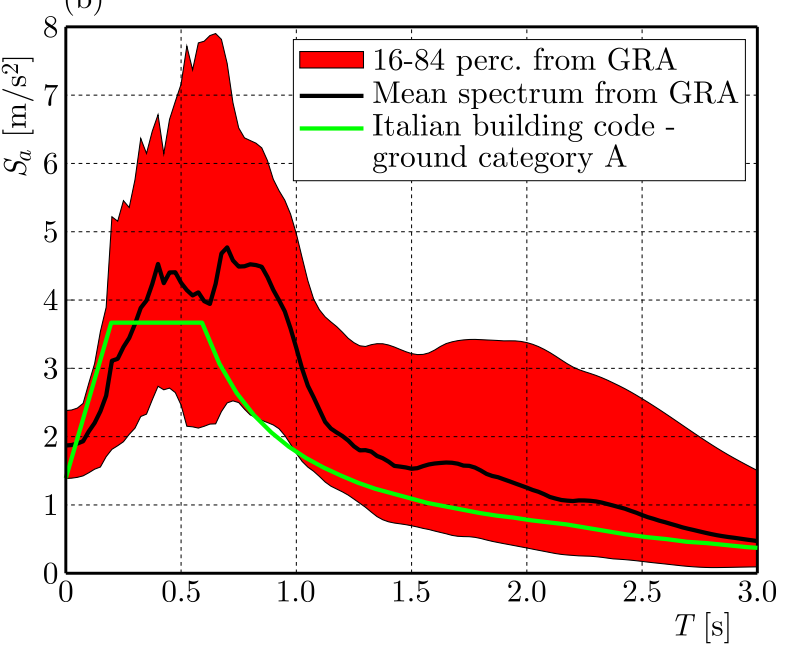

Fig. 5. Stochastic ground response analysis for zone Z.1 (extension of the secondary runway) in the airport area: mean acceleration response spectra (black line) plus and minus one standard deviation (red area) referred to 475-year (a) and 2475-year (b) return periods, respectively. The spectra of Italian building code (NTC, 2018) for ground category A (rocky site) are also shown 
The mean of $5 \%$ damped, elastic acceleration response spectra (together with plus and minus one standard deviation bands) are plotted in Fig. 5, referring to 475-year (a) and 2475-year (b) return periods, respectively. In order to show the level of amplification present in the acceleration response spectra computed at the surface, they are also compared with the spectra prescribed by the Italian building code (NTC, 2018) for ground category A (rocky site) adopted in definition of the reference seismic hazard (see Section 3.1).

Predictions currently obtained from stochastic ground response analyses show that the litho-stratigraphic amplification turns out to be slightly higher at Z.1, Z.2, and Z.3 (spatial distributions of the zones are shown in Fig. 3) with respect to other zones within the airport area.

\section{Concluding remarks}

This study focused on the definition of a free-field seismic input at the ground surface for an international airport in Italy. Summary of steps followed to carry out analyses and salient insights obtained from the results are listed with the bullet points shown below:

- The airport area is characterized by a significant soil variability. This is mostly due to the geological framework because the airport lies on a complex alluvial subsoil system.

- Within the airport area, different homogeneous zones from a seismic geotechnical viewpoint were identified in this study and, then, 1D soil models built for each zone. In doing this, a seismic microzonation map of the airport area was delivered.

- For each zone, 1D fully stochastic site response analyses (1000 simulations) were carried out by using the Stoch-Shake code set-up at Eucentre, capable to account for uncertainty of soil model parameters as well as variability of the seismic input.

- Although seismicity at the site of the airport is moderate, the dynamic response of soils is nonlinear even at low to moderate deformation levels. Thus, these manifestations of soil behaviour have been taken into account using a linear-equivalent constitutive model.

- Finally, this study illustrates an approach to quantify the spatial variability of effects of ground amplification and, thus, of modification of the reference outcrop motion due to local site conditions with reference to a large airport area. Litho-stratigraphic amplification turns out to be slightly higher along secondary runways of the airport with respect to other zones under investigation.

The work presented in this paper has been carried out within the framework of an inter-institutional collaboration in Italy involving the Department of Civil Protection, the Civil Aviation Authority, and Eucentre. GIS-based tools are currently under development to assess earthquake-related damage to airports starting from definition of the seismic hazard and accounting for contribution of ground effects. The final goal is to ensure a homogenous and composite flow of data and results of analyses (e.g. seismic damage scenarios, etc.) through the webGIS platform purposely-developed at Eucentre, shared with the main stakeholders such as DPC and ENAC.

In this framework, the webGIS platform represents a valid support to decision makers in the development of mitigation and prevention strategies, plans of intervention and post-earthquake emergency management.

\section{Acknowledgements}

This work has been carried out under financial auspices of the Department of Civil Protection of Italian Government within the sub-project named "Seismic risk of airports". This support is gratefully acknowledged by the authors. Special thanks go to prof. Mauro Dolce.

We would like to express our gratitude to the staff of the Airport Authority who kindly provided technical data. Finally, the support provided by the technical staff at Eucentre, in particular eng. Antonino Famà and dr. Elisa Zuccolo, is gratefully acknowledged by the authors. 


\section{References}

1. Andreotti G., Famà A., LAi, C.G., 2018, Hazard-dependent soil factors for site-specific elastic acceleration response spectra of Italian and European seismic building codes, Bulletin of Earthquake Engineering, 16, 5769-5800, DOI: 10.1007/s10518-018-0422-9

2. Assimaki D., Pecker A., Popescu R., Prevost J., 2003, Effects of spatial variability of soil properties on surface ground motion, Journal of Earthquake Engineering, 7, SI1, 1-44

3. Awojobi A.O., 1975, The settlement of a foundation on Gibson soil of the second kind, Géotechnique, 25, 2, 221-228, DOI: 10.1680/geot.1975.25.2.221

4. Boore D., 2004, Can site response be predicted? Journal of Earthquake Engineering, 8, SI1, 1-41

5. Bozzoni F., Lai C.G., Scandella L., 2012, 2012 Emilia earthquakes: preliminary results of ground-motion characteristics, Annals of Geophysics, 55, 4, 609-614, DOI: 10.4401/ag-6121

6. Bozzoni F., Scandella L., Lai C.G., Corigliano M., 2011, Assessment of the seismic damage of maritime ports by using GIS technology: the case study of the port of Salerno (in Italian), Progettazione Sismica, 1, 1, 117-137

7. Circ. NTC, 2019, Instructions to apply the Italian Building Code 2018 (in Italian), C.S.LL.PP, G.U. n.35 11/02/2019

8. Corigliano M., Lai C.G., Rota M., Strobbia C., 2012, ASCONA: Automated selection of compatible natural accelerograms, Earthake Spectra, 28, 3, 965-987, DOI: 10.1193/1.4000072

9. Darendeli M.B., 2001, Development of a new family of normalized modulus reduction and material damping curves, Ph.D. thesis, University of Texas at Austin, Austin, TX

10. DPR, 2015, Identification of airports of national interest (in Italian), Decreto del Presidente della Repubblica, G.U. n. 294 18/12/2015

11. EN 1998-1, 2004, Eurocode 8: Design of structures for earthquake resistance - Part 1: General rules, seismic actions and rules for buildings

12. Eurocode 8, 2003, Design of structures for earthquake resistance, Part 1: General rules, seismic actions and rules for buildings, Pr-EN1998-1, European Committee for Standardization (CEN), Brussels

13. FACCIOLI E., 1991, Seismic amplification in the presence of geological and topographic irregularities, Proceedings International Conference on Recent Advances in Geotechnical Earthquake Engineering and Soil Dynamics, St. Louis, Missouri, 1779-1797

14. Gibson R.E., 1967, Some results concerning displacements and stresses in a non-homogeneous elastic half-space, Géotechnique, 17, 1, 58-67, DOI: 10.1680/geot.1967.17.1.58

15. IDRISS I.M., 1990, Response of soft soil sites during earthquakes, Proceedings of H. Bolton Seed Memorial Symposium, J.M. Duncan (Edit.), 2, 273-290

16. ISSMGE, 1999, Manual for Zonation of Seismic Geotechnical Hazards - Technical Committee for Earthquake Geotechnical Engineering TC4, The Japanese Geotechnical Society, Tokyo, Japan

17. Kramer S.L., 1996, Geotechnical Earthquake Engineering, Prentice-Hall International Series in Civil Engineering and Engineering Mechanics, 653

18. Lai C.G., Corigliano M., Sanchez H.L., 2009. Some examples of 1D, fully stochastic site response analyses of soil deposits, Proceedings of the ACES Workshop: Advances in PerformanceBased Earthquake Engineering, Corfu, Greece

19. Marchetti S., 1980, In situ tests by flat dilatometer, Journal of the Geotechnical Engineering Division, 106, GT3, 299-321

20. Mayne P.W., 2007, NCHRP Synthesis 368: Cone Penetration Test, Transportation Research Board, National Academies Press, Washington DC, 118. www.trb.org 
21. Meyer M.E., Tan C.K., Drumheller L.C., 2001, Liquefaction mitigation at JFK Airport using dynamic compaction, [In:] Foundations and Ground Improvement, Geotechnical Special Publication, 113, $685-700$

22. Moravej M., VAfaei M., 2019, Seismic performance evaluation of an ATC tower through pushover analysis, Structural Engineering International, 29, 144-149, DOI: 10.1080/ 10168664.2018.1468229

23. Nisqually Earthquake Clearinghouse Group, 2001, The Nisqually Earthquake of 28 Febbuary 2001, Preliminary Reconnaissance Report, University of Washington, WA (USA)

24. NTC, 2018, Italian Building Code (in Italian), Decreto Ministeriale, G.U. n. 42 20/02/2018

25. Paolucci R., Mazzieri I., Smerzini C., Stupazzini M., 2014. Physics-based earthquake ground shaking scenarios in large urban areas, [In:] Perspectives on European Earthquake Engineering and Seismology, 331-359, Springer, Cham

26. Robertson P.K., 2016, CPT-based soil behaviour type (SBT) classification system - an update, Canadian Geotechnical Journal, 53, 12, DOI: 10.1139/cgj-2016-0044

27. Rota M., Lai C., Strobbia C., 2011, Stochastic 1D site response analysis at a site in central Italy, Soil Dynamics and Earthquake Engineering, 31, 4, 626-639, DOI: 10.1016/j.soildyn.2010.11.009

28. Rota M., Zuccolo E., Taverna L., Corigliano M., Lai C.G., Penna A., 2012, Mesozonation of Italian territory for definition of compatible accelerograms, Bulletin of Earthquake Engineering, 10, 1357-1375, DOI: 10.1007/s10518-012-9369-4

29. Schnabel P.B., Lysmer J., Seed, H.B., 1972, Shake: A Computer Program for Earthquake Response Analysis of Horizontally Layered Sites, Report No. UCB/EERC-72/12, University of California

30. Spallarossa D., Barani S., 2007, Disaggregazione della pericolositá sismica in termini di M-R- $\varepsilon$, DPC-INGV S1 Project: http://esse1.mi.ingv.it/d14.html

31. Stucchi M., Meletti C., Montaldo V. Crowley H., Calvi G.M., Boschi E., 2011, Seismic hazard assessment (2003-2009) for the Italian building code, Bulletin of Seismological Society of America, 101, 4, 1885-1911, DOI: 10.1785/0120100130

32. Tarque N., Lai C.G., Bozzoni F., Miccadei E., Piacentini T., Camata G., Spacone E., 2013, Expected ground motion at the historical site of Poggio Picenze, Central Italy, with reference to current Italian Building Code, Engineering Geology, 166, 8, 100-115, DOI: 10.1016/j.enggeo.2013.09.003

33. Vafaei M., Alih S.C., 2018, Seismic vulnerability of air traffic control towers, Natural Hazards, 90, 803-822, DOI: 10.1007/s11069-017-3072-3

34. Wilcoski J., Heymsfield E., 2002, Performance and rehabilitation of type L FAA airport traffic control tower at San Carlos, California, for seismic loading, Journal of Performance of Constructed Facilities, 16, 2, 85-93, DOI: 10.1061/(asce)0887-3828(2002)16:2(85)

35. Zembaty Z., Kokot S., Bozzoni F., Scandella L., Lai C.G., Kuś J., Bobra P., 2015, A system to mitigate deep mine tremor effects in the design of civil infrastructure, International Journal of Rock Mechanics and Mining Sciences, 1, 74, 81-90, DOI: 10.1016/j.ijrmms.2015.01.004 